\title{
AN APPARATUS FOR THE QUANTITATIVE COLLECTION OF URINE FROM WOMEN
}

\author{
OTTO FOLIN, M.D., and W. DENIS, Ph.D. \\ BOSTON
}

The difficulty, in fact, we may almost say the practical impossibility, of obtaining accurate twenty-four-hour quantities of urine from female hospital patients has probably been recognized by every investigator who has attempted to conduct metabolism experiments on this class of subjects. Our own experience has been that even when under the constant supervision of competent nurses, intelligent female patients (particularly when under the influence of cathartics) will frequently lose from 5 to 25 per cent. of the daily amount of urine.

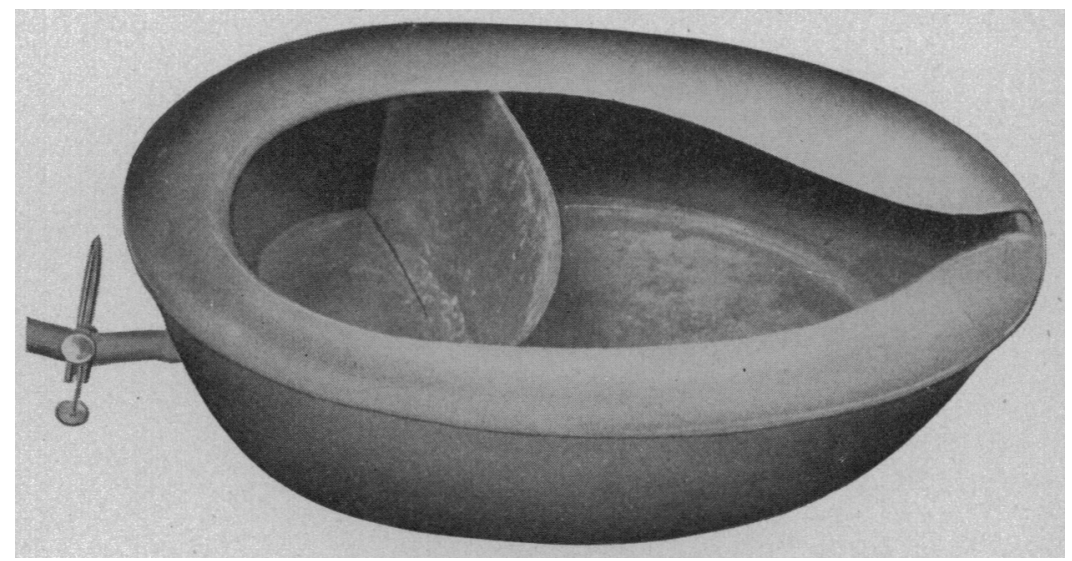

Apparatus for quantitative collection of urine from women.

In order to overcome this difficulty we have devised a "divided pan," an illustration of which is shown. This pan, which is made of sheet copper, nickel plated, is constructed along the lines of the ordinary hospital bed pan, being 14 inches long by $93 / 4$ inches wide; the front end is $4 \frac{1}{4}$ inches high, the back $91 / 2$ inches; $6 \frac{1}{4}$ inches from the front end is a curved slanting partition which divides the vessel into two chambers, one for the reception of urine, the other for feces. The front or urine compartment is provided with an outlet consisting of a short piece of copper tubing half an inch in diameter and closed by means of a piece of rubber tubing and a pinchcock. The top of the pan is so constructed that it may be easily removed for cleaning. 
We have now had this apparatus in use for many months in the women's and children's wards of the Massachusetts General Hospital, during which time it has been used by a large number of patients with practically invariable success. It may be used in bed with the subject in the recumbent position, or in the case of patients well enough to be up and about the ward, may be placed on a low stool.

While the device was introduced primarily for our metabolism experiments, it has been found useful in many cases in the routine collection of urine or feces, particularly in the case of very stupid patients and those unable to speak English.

Harvard Medical School. 